IZA DP No. 4888

Children's Schooling and Parental Migration:

Empirical Evidence on the "Left Behind"

Generation in Albania

Gianna Claudia Giannelli

Lucia Mangiavacchi

April 2010 


\title{
Children's Schooling and Parental Migration: Empirical Evidence on the "Left Behind" Generation in Albania
}

\author{
Gianna Claudia Giannelli \\ University of Florence, \\ CHILD and IZA \\ Lucia Mangiavacchi \\ University of the Balearic Islands \\ and Paris School of Economics
}

Discussion Paper No. 4888

April 2010

IZA

P.O. Box 7240

53072 Bonn

Germany

Phone: +49-228-3894-0

Fax: +49-228-3894-180

E-mail: iza@iza.org

Any opinions expressed here are those of the author(s) and not those of IZA. Research published in this series may include views on policy, but the institute itself takes no institutional policy positions.

The Institute for the Study of Labor (IZA) in Bonn is a local and virtual international research center and a place of communication between science, politics and business. IZA is an independent nonprofit organization supported by Deutsche Post Foundation. The center is associated with the University of Bonn and offers a stimulating research environment through its international network, workshops and conferences, data service, project support, research visits and doctoral program. IZA engages in (i) original and internationally competitive research in all fields of labor economics, (ii) development of policy concepts, and (iii) dissemination of research results and concepts to the interested public.

IZA Discussion Papers often represent preliminary work and are circulated to encourage discussion. Citation of such a paper should account for its provisional character. A revised version may be available directly from the author. 
IZA Discussion Paper No. 4888

April 2010

\section{ABSTRACT \\ Children's Schooling and Parental Migration: Empirical Evidence on the "Left Behind" Generation in Albania*}

This article investigates the long-term effects of parental migration abroad on the schooling of children left behind in Albania. Although parents' migration usually benefits children economically, the lack of parental care may cause relational and psychological problems that may affect children's welfare in the long-term. The phenomenon of children left behind mainly by fathers - is very relevant in Albania where migration has represented the only viable way to cope with increasing poverty and the absence of public resources for sustaining households' incomes. Between 1990 and 2005 in Albania 21.7\% of children under 18 have been left behind, with an average parental absence of 9.5 months. Using detailed information on family migration drawn from the Living Standard Measurement Survey for 2005, multiple choice models are applied to evaluate the school progression of older children and adolescents. A duration analysis of school participation with both discrete and continuous time models is then performed. The results show that past parental migration has a negative effect on school attendance in the long-term with higher hazards of school drop-outs for children left behind. These results are robust to the use of different econometric techniques and model specifications.

JEL Classification: J13, J18, O15, P36

Keywords: children, schooling, migration, duration analysis, Albania

Corresponding author:

Gianna Claudia Giannelli

University of Florence

Department of Economics

Via delle Pandette 9

50127 Firenze

Italy

E-mail: giannelli@unifi.it

\footnotetext{
* The authors would like to thank Tindara Addabbo, Arnab K. Basu and Maria Sassi for the very valuable comments and suggestions.
} 


\section{Introduction}

The implicit assumption in most of the existing studies on migration and child welfare is that migration affects children's outcomes only by alleviating household's budget constraints thanks to remittances. Several recent empirical studies have shown the positive effects of remittances on human capital investment. These studies follow the literature on the schooling of children in developing countries, which has emphasized the role of family income constraints by explaining differences in child welfare and human capital development. They extend this approach to migration studies, evaluating the impact of remittances as an additional source of income. For example Edwards and Ureta (2003) in a study based on data from El Salvador found that remittances reduced the hazard of school drop-outs and Calero et al. (2009) similarly show that remittances increased school enrolment and reduced child labour in Ecuador.

The theoretical literature on "beneficial brain drain" (Stark et al., 1997) is an additional point of view on the relationship between migration and human capital: the prospect of higher returns to education in a foreign country boosts investment in human capital at home. In this line of research Stark and Wang (2002) developed a theoretical analysis of how migration can substitute the provision of public subsidies for the growth of human capital.

On the other hand, recent studies provide mixed evidence on whether migration has a net positive or negative effect on child development. The positive impact on financial constraints deriving from income earned abroad are not without side effects. The parents' absence may be a psychological cost and change the decision-making process within the household. When a household member leaves, intra-household duties and responsibilities may change. Children of migrant parents may spend less time on school-related activities and their involvement in work tasks may increases. Consequently they may drop out of school or be held back a grade or more, due to non-completion or unsatisfactory completion of their work. Recent empirical works have addressed this issue, finding negative impacts on child welfare that emerge during or after the migration process. Hildebrandt and McKenzie (2005) show that migration has a negative effect on the likelihood of breastfeeding and vaccinations; similarly, Kiros and White (2004) find that children of migrant mothers in Ethiopia have less chances of receiving full immunization coverage than children of non-migrant mothers. McKenzie and Rapoport (2006) examining the impact of migration on educational attainment in rural Mexico, found that living in a migrant household lowers the chances of children completing high school. They attribute these outcomes to side effects of migration and in particular to the fact that the absence of parents in the household due to migration could lead to reduce investment in their children's education. The presence of a causal relation between parental absence and children's schooling is a common result in the studies on divorce and separation aftermaths. Del Boca (2003), for instance, focusing on the welfare of children of divorced parents, calls for extensive public support for children who are made vulnerable by divorce. Theoretical and empirical analyses assessing from an economic point of view the impact on children of parental absence are also those considering the child's orphan status in developing countries. Among them, the empirical study by Yamano et al. (2006) 
on Uganda's orphans which focuses on outcomes for primary school children and adolescents. They estimate schooling enrolment and school progression, finding even greater negative effects for older children.

If the main theoretical argument for the negative impact on child welfare of migration is parental absence, the major limitation of the analyses on the relationship between migration and schooling is that they are not able to disentangle the effect of parental migration from the child's own migration experience, mostly because of poor survey information. Liang and Chen (2007), addressing the phenomenon of children left behind, are able to distinguish children involved in permanent migration from children who remain at home in China and find that the first ones have a higher likelihood of being enrolled in school.

Parental migration when the child is left in the country of origin has long-term implications for his/her development and his/her future life. These include, for example, changes in household structure and responsibilities leading to more pressure on older children to help in the household or to assist with agricultural duties and so neglect their schooling. Effects such as the break-up of the family and a lack of parental supervision and social interaction have also to be considered. These disruptive effects on family structure can change the leadership in the family, giving more power to older males who are less educated and less prone to understand the importance of investment in human capital as regards to their grandchildren (Ginther and Pollak, 2004), thus the possible long-term effects of migration might cancel out the effects of a temporary improvement in household incomes.

The children "left behind" phenomenon has become of growing importance in the last decades in Albania and it is recorded on microdata by the World Bank Living Standard Measurement Survey. Unlike other surveys, ALSMS 2005 allows us to reconstruct the "left behind" episodes of children in the migration history of their parents. This gives two advantages with respect to previous analyses: the status of the child during parental migration can be consistently recovered, and even if the survey is a cross-section, retrospective information on migration is collected, so that the long-term effects of the phenomenon can be identified accurately. Concerning children's outcomes, we use firstly school attendance and a grade-for-age indicator for children and adolescents. Secondly, as in Pudney et al. (2006) and in Edwards and Ureta (2003), the present underinvestment in human capital is represented by the hazard of dropping out from school.

The analysis is conducted on two separate groups: primary school-age children and adolescents. With regard to the econometric method, the school progression of children and adolescents is studied using an ordered choice model. Finally, the analysis was focused on schooling attendance and a duration model for school participation was estimated.

The study is organized as follows: Section 2 deals with the children "left behind" phenomenon in Albania, Section 3 describes the data and variables used in the analysis, Section 4 explains the econometric tools used and Section 5 shows the results. Section 6 concludes. 


\section{The "left behind" generation in Albania}

Albania is a good field laboratory to study the effects of parental migration on children schooling because of the characteristics of the migration and the education system.

In the past fifteen years, one in three Albanian households has experienced a migration abroad with a positive impact on household consumption and poverty reduction thanks to a massive surge of remittances (WB, 2007). A considerable amount of children have been left behind by seasonal or permanent migrant parents. A recent analysis of the phenomenon by UNICEF (2009) has led to concern for the magnitude of the phenomenon both in Albania and in the Republic of Moldova. While in the latter country children are more affected in general, the incidence of the phenomenon is larger in Albania if one focuses only on young children. The main difference between the two countries is that the "left-behind" phenomenon in Moldova is associated with the so-called "care drain" towards western European countries, which means that large numbers of children are being left behind by their mothers, probably resulting in even tougher effects. In Albania, on the other hand, migration has been male-dominated and what is observed in the majority of cases is the absence of the father. The WB (2007) claims there is a negative effect of migration on children's outcomes in Albania. In rural areas, daughters of permanent international migrants (aged 6-22 years) have lower enrolment rates than those living in households without international migrants. This suggests the presence of side effects of migration on children's schooling. It is also being found that households with permanent international migrants spend less on education. In spite of these concerns and the relevance of the phenomenon, there are no public subsidies supporting households with children where members have emigrated abroad.

An analysis of the schooling record is also of particular interest in Albania, since in the last fifteen years a significant drop in enrolment, especially from secondary school, has been observed due to transition. Even when the importance of family income and scarcity of schools in determining school attendance increased during the 90s, the drop in enrolment is also due to a lack of interest caused by the judgement of low quality of education. New cultural barriers to female education $^{1}$ are also a factor to consider. Public expenditure on education is ineffective and there are no other kinds of subsidies successfully supporting family with children (WB, 2006; Mangiavacchi and Verme, 2009) and at the same time the education sector is still subject to a lack of basic infrastructure. Picard and Wolff (2008) found that education is costly for households, and education inequality is relevant within families and even more between families. Generalised education in Albanian really began only under communism when children's education progressed dramatically (Picard and Wolff, 2008). Transition and the consequent civil disrup-

\footnotetext{
${ }^{1}$ With the transition, the traditional patriarchal values of the Albanian household acquired renewed relevance with a dominant role of men over female and consequently less attention to the investment in human capital for girls ( Danaj et al. (2005)). The household is the only institution in the country able to protect vulnerable individuals, however, at the same time it has been experiencing big cultural changes in the last fifty years, with consequent problems for women and the youth in the always difficult balance between traditional norms and modernity (see Gjonca et al., 2008, for an demographic analysis of Alabnia).
} 
tion experienced by the country produced many problems to the education system (destruction of education buildings, schools unstaffed in rural areas, corruption mainly due to inadequate teachers' salaries). Since 2000s learning conditions were improved with the reconstruction of many schools, albeit the quality of teaching is still poor and corruption has not been eradicated at all educational levels.

\section{Data and variables}

The main reason for the lack of research on the impact of migration on children is the scarcity of detailed data in the same survey on both international migration and children's welfare. The data for Albania used in this study contains detailed information on the children left behind by parents who migrate abroad - with retrospective information that facilitates a dynamic analysis of the phenomenon - and to explore its long-term effects. The analysis of this article is based on the 2005 Albanian Living Standards Measurement Study survey. Unlike other household surveys, the LSMS provides unusually detailed information on the migration of both current and former household members. Moreover, the Albanian LSMS includes information on a wide range of demographic and socio-economic characteristics at household and individual levels, as well as a community questionnaire with information on local services and socio-economic conditions. A total of 3,640 households were interviewed, amounting to a national representative sample of 17,302 individuals, 33.75\% of which were children (under 18 years old). Even if the questionnaire is very thorough and contains detailed information on education, health, social capital and consumption expenditure, the survey has a limited focus on children, and it is difficult to recover qualitative child wellbeing indicators. For instance, there is good information on service availability, quality and adequacy, but limited information on the demand for schooling and the factors influencing this demand. However, the migration module provides detailed information on the individuals' migration history and behaviour toward children during the migration episodes.

A sample of 5,834 children is drawn from the 2005 LSMS, and the analysis is conducted on two different sub-samples. First, a sample of 2,575 compulsory school-age children equally distributed between boys and girls, with an enrolment rate of $90 \%$, of whom $22 \%$ had been left behind. Second, a sample of 1,898 adolescents aged from 14 to 18, $67 \%$ of whom were attending secondary school and up to $19 \%$ of whom had experienced an episode of parental absence due to parental international migration.

The chosen children's wellbeing indicators that may be affected by the "left-behind" episodes relate to education (see in Table 1) are the school attendance and the "school progression" of 6 to 13 years old children and 14 to 18 years old children. Following Orazem and King (2008), school participation is analysed first using the questions on both enrolment ${ }^{2}$ and attendance ${ }^{3}$; then the dichotomic variable is transformed into an ordinal categorical variable for not attending,

\footnotetext{
2 "Did you enroll in school this academic year?"

3 "Are you currently attending school?"
} 


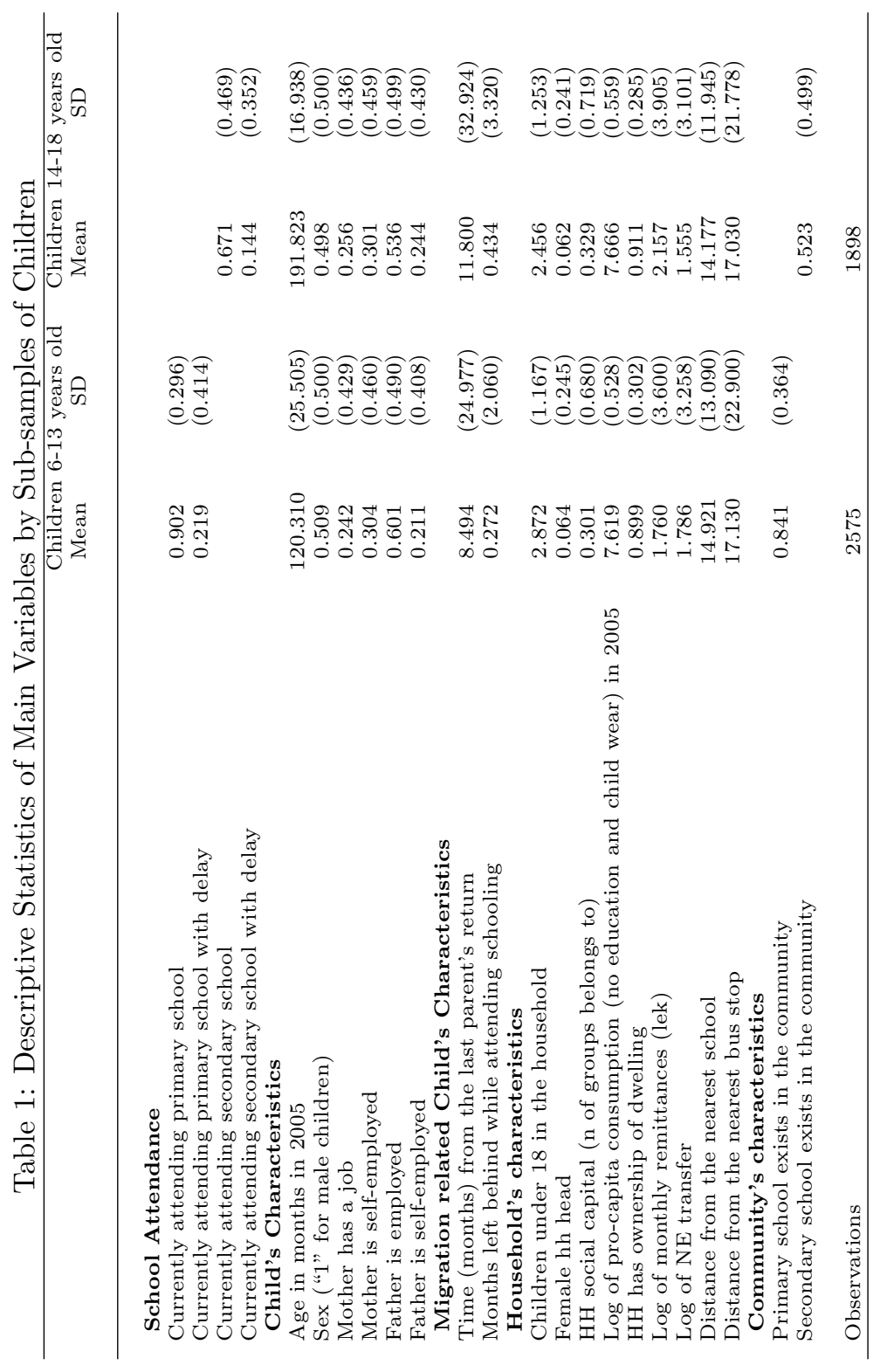


attending with delay, in-time attendance ${ }^{4}$; for the scope of the analysis, it is important to capture these differences. The outcome of enrolment with delay reflects a confluence of factors including supply side problems, school governance and household demand ${ }^{5}$. Within the primary school sample, $9 \%$ of children are not attending school at all and up to $22 \%$ are attending with delay, while in the adolescent sample the share who does not attend a secondary school program is $32 \%$, and that of those who attend with delay is $15 \%$.

The explanatory variables applied in this analysis may be classified into five groups: variables that have to do with a child "left behind" episode, variables related to children's individual characteristics, variables regarding household socio-economic conditions, territorial variables and policy variables.

The main indicator of a left-behind episode is the variable "months of left behind", shown in table 1. The variable has been constructed from the module on past migration episodes, where returned individuals are asked if their children were living with them abroad or if they had remained in Albania ${ }^{6}$. The durations of the most recent and of the first migration episodes are recorded, so that they can be summed up to derive the total amount of months in which a child has been left behind. The variable has been created without distinguishing between maternal and paternal migration. The observations referring to absence of the mother are too few to be used separately from fathers absence so they are pooled. Children left in the past by parents who had returned (and were present at the moment of the survey) amount to 1,160. Moreover, the survey informs if any of the non-present members (children or spouses of the head of household) were living away from their children at the moment of the interview. In integrating the variables of past "left behind" episodes with the information on children presently left behind, almost all the "left behind" episodes from child birth ${ }^{7}$ to the moment of the interview have been recovered. Additionally, this variable, when used for children older than $5^{8}$, has been adjusted for school-age children, eliminating the left-behind episodes that may have occurred before school creating th variable "months left behind while attending school" (Table 1). The variable has been transformed to " 0 " for these cases to control for temporal consequentiality when estimating the

\footnotetext{
${ }^{4}$ Orazem and King (2008) note that two children of the same age who are both enrolled could be in different grades because one may have started school later or may have dropped out for a short time or repeated a year. To proxy delayed attendance variable indicating the "theoretical" maximum number of months a child should have been attending at each level and year, compared it with the effective number of months each child has been attending school to reach their level. The variable takes " 0 " if the child is not attending school, " 1 " if he/she attending but has experienced delayed enrolment or repeated a year, and " 2 " for in-time enrolment.

${ }^{5}$ As noted in the previous section when a household member leaves, intra-household duties and responsibilities may change, and children of migrant parents may spend less time on school-related activities.

${ }^{6}$ The question is "Were any of your children living with you during your stay abroad?", thus, for those who responded "No, lived in this household", it is sure that all of the children remained at home during the migration. Inversely, for the 171 individuals who responded that any of their children had emigrated with them, it was not possible to control for brothers and sisters' remaining at home. Because of the 171 "yes" cases, 141 referred to the migration of both parents, it can be assumed that nearly all of the children were with the parents in those cases. In conclusion, there are 30 cases in which the number of children left behind may have been underestimated.

${ }^{7}$ The migration episodes that are considered in the analysis are only those after the beginning of Albanian transition (1990)

${ }^{8}$ For children older than 5 the survey reports information on the year they had left school.
} 
effect of a left-behind episode on schooling attendance ${ }^{9}$ and to keep the identification condition working.

A limit of the survey is that the question about children left behind was asked only for the most recent episode of migration and for the very first. It is not possible to know if the father or the mother have left their child more than twice. For those individuals in the survey who experienced other migration episodes between the first and the last, it is not known if they had children who had been left behind ${ }^{10}$.

Using the described variables we are able to define the magnitude of the "left behind" phenomenon which is very huge for Albania. Between 1990 and 2005 in Albania 21.7\% of children under 18 have been left behind, with an average parental absence of 9.5 months. The share of primary school children is of $24.6 \%$, with 9.28 months of absence while the $21.3 \%$ of secondary school children (aged between 14 and 18) has suffered the lack of parental care, with average abandonment of 12.18 months. After an episode of being left behind the $35.6 \%$ of primary school children did not attend and the $17.8 \%$ attended school with delay while almost all the adolescents (the $93.3 \%$ ) left behind in the past did not attend school in 2005.

Among the individual variables, are age in months, gender, years of pre-school attended for school-age children, educational background and the employment status of the mother and father. Cultural and religion variables, together with main household characteristics, are also used in the analysis. The logarithm of per-capita household consumption is among them, from which child expenditure (education and wear) has been eliminated to avoid problems of endogeneity, and also value of remittances during the year of the survey ${ }^{11}$. Variables indicating the distance of the household from some services are also used. To derive an indicator of child social skills, detailed survey information on the number of informal groups the household is member of are used. Unfortunately, this module is responded by the household head for all household members. Thus, it is not a specific proxy of children's networks or social capital. Nevertheless social capital may be introduced as a household feature among the explanatory variables.

As residence variables, dummies for "Tirana", "coastal rural/urban area" , "central ru$\mathrm{ral} / \mathrm{urban}$ " area and "mountain urban/rural area" according to the first stratification unit of the survey sample are used ${ }^{12}$.

The effect of public intervention is also controlled for using two main variables. The first is a dummy for the child who lives in a household that participates in a mean tested family allowances program (the Ndhdime Ekonomike). The second is a dummy for the presence of the

\footnotetext{
${ }^{9}$ For this adjustment the question regarding the last year of school attended by those who have dropped out has been used.

${ }^{10}$ However, only 4 children in the sample who had been left behind the first and the last time have their parents with a third migration episode, and thus all periods of parental absence, except these 4 , for which the duration of parental absence may have been underestimated, cab be reasonably be assumed to have been captured.

${ }^{11}$ Note that this variable being current, not controlling for the economic effect of past migration on present child wellbeing. The variable "remittances" is used here to control for the general economic effects of migration, which are also likely to be persistent over time thought savings.

${ }^{12} \mathrm{It}$ is not possible to use a smaller territorial unit in order to keep statistical properties of a large sample in the econometric analysis
} 
pre-school, primary school or secondary school in the municipality ${ }^{13}$.

An additional variable is the occurrence of a particular shock that may have affected the household during the transition. Households are requested to report the exact year of the shock. In particular, the following shocks are taken into account: the death of an earner within the family, a job loss for the household head, the physical destruction of the house and significant monetary losses due to the financial "pyramid crisis" of 1997.

\section{Estimation strategy}

Since both attendance and progression are studied in our analysis and moreover we want to capture long-term effect by being left behind on schooling, a series of estimates with different models are proposed, with the aim of reliable evidence on the correlation between human capital growth and the state of children in migrant families.

Primary school is mandatory, hence participation should be almost universal. However, several cases of delay in school participation and a few cases of school drop out are observed. On the other hand, secondary schools are not mandatory, hence many more cases of drop out are observed. These differences suggest that it is safer to conduct two separate analyses for mandatory school children (aged 6 to 13 years old) and secondary school children (aged 14 to 18 years old). For both groups, however, the estimation techniques are the same.

For these children, school participation is modelled in three stages: 0 for non-participation, 1 for delayed participation and 2 for regular participation. This variable is called "school progression". The idea is to have different degrees of failure of school participation, which include a delay in the completion of studies and the departure from schooling.

This situation is modelled using an Ordered Logistic Regression (McCullagh, 1980). With this model, a hierarchy for the dependent variable categories meaning is assumed, for example, that 1 is better than 0 and 2 is better than 1 . This seems to be the case given how the schooling participation variable is constructed. The results for both primary school children's and secondary school children's schooling progression are presented in Table 3 .

In order to analyse the relation between school drop out and having been left behind in a longitudinal dimension we exploit retrospective informations on schooling and migration estimating a series of duration models (see Jenkins, 2004, for an exhaustive review) in line with the work of Edwards and Ureta (2003), who estimated the impact of remittances on school drop-outs. This choice has been dictated by the actual structure of the data. In fact, differently by Edwards and Ureta (2003) who do not have retrospective data, both the relevant episodes, namely dropping out of school and having been left behind can be recovered from the migration history of parents and education history of children available in the Albanian LSMS. With these data, the choice of duration models applied to the schooling period appears particularly appealing.

The observed lifetime corresponds to the time that the children spend in school (spell), and

\footnotetext{
${ }^{13}$ This information is shown from the community questionnaire.
} 
death corresponds to the observed drop out on the part of the child (failure). The probability of quitting the spell of education (failure) may be influenced by a number of exogenous factors.

Before proceeding to describe the estimated models, it is useful to present the basic concepts related to survival analysis to clarify the differences between them. The length of a spell for an individual is stochastic and denoted by $T$. Its cumulative distribution function is $F(t)=$ $\operatorname{Pr}(T \leq t)$, and its probability density function is $f(t)=\partial F(t) / \partial t$. The survival function $S(t)$ is defined as $1-F(t)$ and denotes, in a broad sense, the probability of survival up to $t$.

The hazard function can be defined as the rate at which the spell is completed at time $t$ given that it has not been completed before $t$, i.e.

$$
\theta(t)=\frac{f(t)}{1-F(t)}=\frac{f(t)}{S(t)} .
$$

The value taken by the hazard function at a particular value of $t$ is called the hazard rate.

The hazard function is in some sense the heart of econometric duration analysis for several reasons. For instance, the fact that in economics the focus is often placed on the rate at which the subject leaves the state at $t$, in particular in trying to explain the hazard at $t$ in terms of external conditions, suggests that one should build all theory around $\theta(t)$. Whatever the reason, the consequence is that different models of duration arise from different specifications of the hazard function $\theta(t)$.

The first fundamental problem in estimating $\theta(t)$ is whether $t$ should be considered a continuous variable or a discrete variable. In principle, almost all spells of interest would be a function of continuous time but are recorded in a convenient time span as days, months or years. In practice, discrete time modelling is used when the length of the spell takes few values, such that a continuous time modeling could be a bad approximation of the data generation process. Secondly, $\theta(t)$ may be characterized by the shape of the functional form chosen. This can be parametric, as in the Weibull, Exponential, Gompertz, Log-Logistic, Lognormal and Generalized Gamma models or semi-parametric.

A particular class of duration models is called "proportional hazard". These models are characterized by the fact that they satisfy a separability assumption

$$
\theta(t, X)=\theta_{0}(t) \exp \left(\beta^{\prime} X\right)=\theta_{0}(t) \lambda
$$

where $X$ is a vector of covariates; $\theta_{0}(t)$ is the "baseline hazard function", which depends on $t$ but not on $X$ (and hence is common to all persons); and $\lambda$ is a person-specific non-negative function of covariates $X$, which scales the baseline hazard function. When the estimation of $\theta_{0}$ is conducted non-parametrically, the model is called Cox's Proportional Hazard model (Cox, 1972). This model is particularly attractive because of the flexibility in the shape of the baseline hazard function and is chosen for the first estimates of school attendance. The results, estimated by Partial Likelihood, are presented in Table 4.

One of the possible weaknesses of this approach is that it may not take sufficiently into 
account the heterogeneity of individuals (often referred to as frailty). If the vector of covariates $X$ is not sufficient to explain the differences in hazard rates among individuals, estimates may be biased. Frailty models overcome this issue by adding an individual-specific error term, as in the random intercepts model. In order to estimate this additional error term, a functional form for its distribution should be specified (common options are the Gamma function and the Inverse Gaussian distribution). Because a Cox estimator with a full frailty implementation is not yet available, the Weibull model is used here to look into the heterogeneity problem. The estimates are presented in Table 4.

Another possible source of error is the fact that some individual characteristics may vary over time. In this case, children have been left behind in a particular moment in their lives, so their hazard rates may have changed in response to this variation. This problem can be solved by including time-varying variables in the estimation of duration models. If a child has been left for one year, than their parent may come back, and leave again and so on. If this is the case, the previous models are likely to be a poor approximation of reality. A possible solution consists in estimating a discrete time duration model that, takes into account the precise point in time when the child has been left behind during the spell of education. The results of the discrete time Cox model ${ }^{14}$ are presented in Table $5^{15}$.

The main concern regarding identification in migration studies (see McKenzie and Rapoport, 2006, and a number of other empirical studies) with respect to children's welfare is the possible endogenous nature of the variable (one can choose to emigrate in order to afford the education expenditure for his/her child). We argue that the our variable "months of being left behind" does not suffer from this problems because of its retrospective nature. In fact, since we observe the complete retrospective history of parental migration and of children's schooling we are able to select children whose parents have emigrated before. As a consequence we estimate as the parental absence affects schooling participation in the long-term and the longitudinal nature of the causal relation would minimize the risk of endogeneity.

\section{Results}

This section presents the estimates of the impact of being left behind on children's schooling by age cohort. The results show that international migration on the part of the father negatively influences his child's schooling in the long-term. The results for primary school children and adolescents (Tables 2 and 3) show negative and significant coefficients for left-behind duration. An additional month left behind increases of $0.8 \%$ the probability of dropping out (outcome 0 ) and of $1 \%$ the probability of attending with delay, while it reduces the probability of in-time enrolment by $1.7 \%$.

\footnotetext{
${ }^{14}$ In order to estimate discrete time duration models, it is necessary to reorganize the dataset in panel form, such that each individual is observed for each time point.

${ }^{15}$ The variable has been corrected in this case for the contemporaneity of the effects and takes the value " 1 " for a left-behind episode the year observed in the data and the next year as a lagged variable.
} 


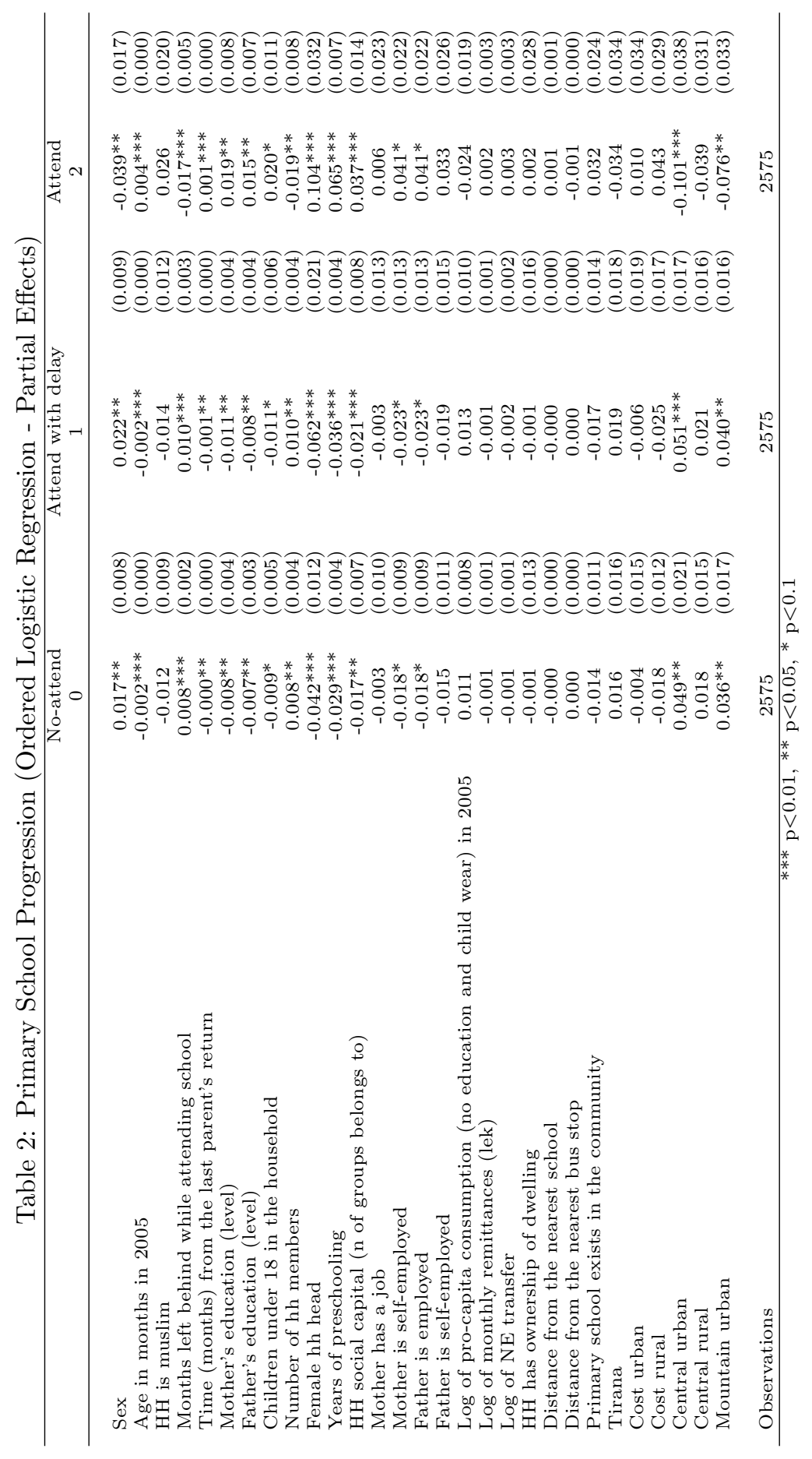


For adolescents the impact is higher: an additional month reduces by $16 \%$ the probability of attending secondary school and increases of $15 \%$ the probability of not being enrolled. The negative impact of the phenomenon is reduced if it is far in the time, as shown by the coefficient of "time since the last return", whereas the effect is increased with the length of the migration episode. These results are reasonable and coherent with the school level attended.

The control variables present the expected sign: children are more likely to drop out school when they are older, less likely to drop out the higher the level of education of their father's and mother's, suggesting the intergenerational transmission of poverty vulnerability and the persistence of education inequality. When the head of the family is female, there is a positive impact in the long-term on children's success at school, particularly in compulsory school, where budget constraints are less relevant. As suggested by other empirical work (Heckman and Masterov, 2007; Alderman et al., 2006), having attended preschool has a positive impact on cognitive development and reduces the risk of drop out or delay for adolescents. The distance of dwelling from public transport has a strongly negative impact on the access to education.

Male children are more vulnerable than females to the risk of drooping out and over-age attendance during primary school. Variables indicating the level of education of parents and the household's social capital are always significant and with a large effect in determining school attendance of both primary and secondary school children.

The economic status of the family (dwelling ownership) influences the frequency of drop-outs as well as employment status of parents ${ }^{16}$, while logistical constraints may be a major reason for delays in primary school attendance. The presence of the school in a particular community is the major element influencing attendance in Tables 2 and 3, while family allowances, ceteris paribus, have no influence.

A Kaplan-Meir estimation of the survival function (Figure 1), computed for the two samples of children who have never been left behind and those who have been, shows that the probability of survival (remaining in the school system) decreases substantially with the duration of the spell for those children who have been left, especially for secondary school. The estimation of the Cox proportional hazard model (Column (1) of Table 4) confirms this result. Being left behind affects the probability of the child's leaving school before s/he reaches 18 years old of age. The other coefficients have almost the same significance levels and signs of the previous model. Female children have smaller probability of surviving in the school system than males, in the long-term. This finding confirm the hypothesis that traditional barriers imposed by the patriarchal society may affect female school participation in spite of the efforts made during the communist era to favour female education. This can be explained in terms of the human capital investment decision, as the investment on female human capital is lost when a daughter leaves her natal household at marriage, becoming part of the husband's family. Column (3) of Table 4 shows the estimates of the parametric frailty model where the hazard function takes a Weibull

\footnotetext{
${ }^{16}$ Danaj et al. (2005) reports an average enrollment rates in secondary school of $40 \%$ with very high drop outs rate. Main reasons are limited availability of schools on rural regions and the need of young people work on family farm.
} 


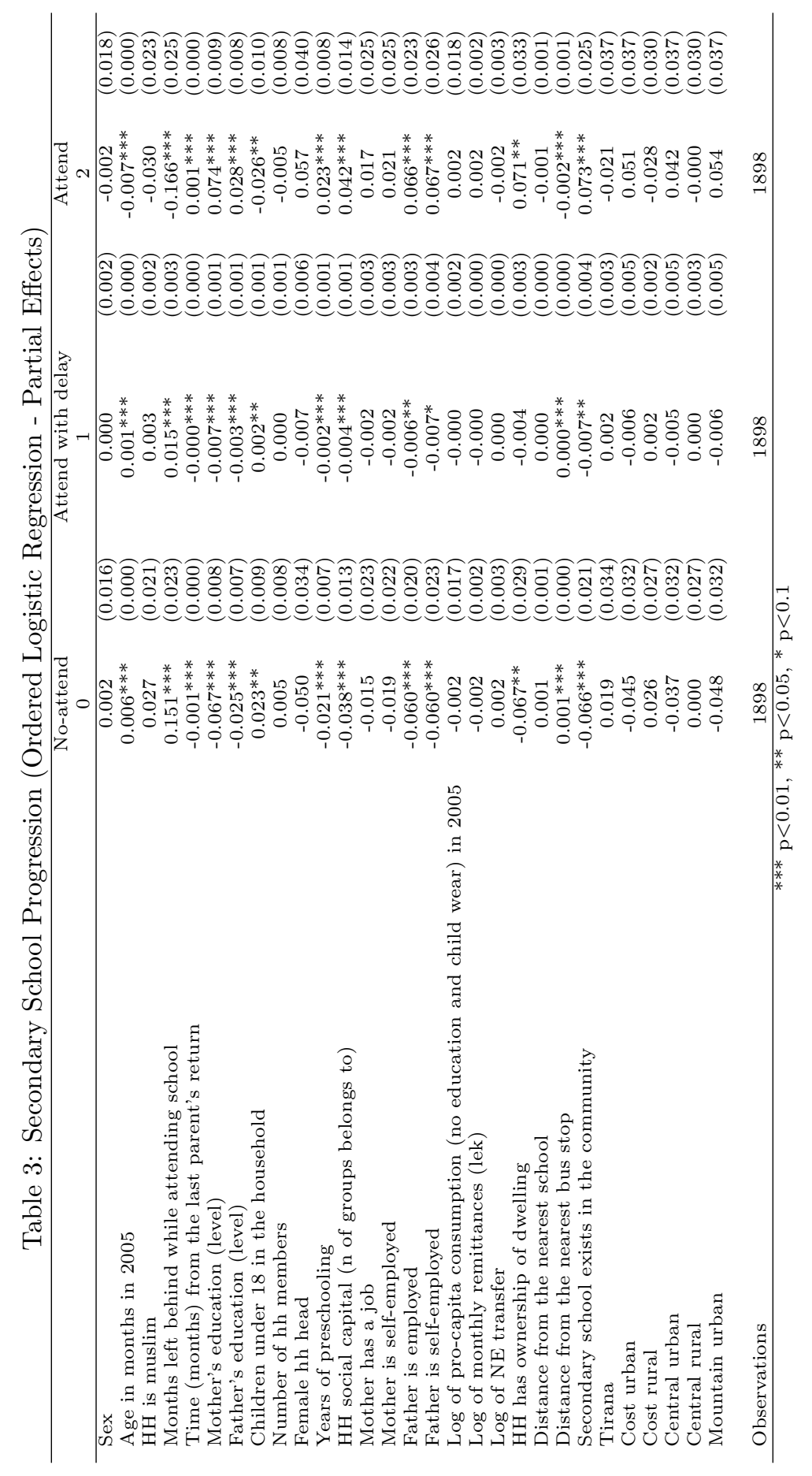


Figure 1: The Kaplan-Meier Estimation of Survival in School System

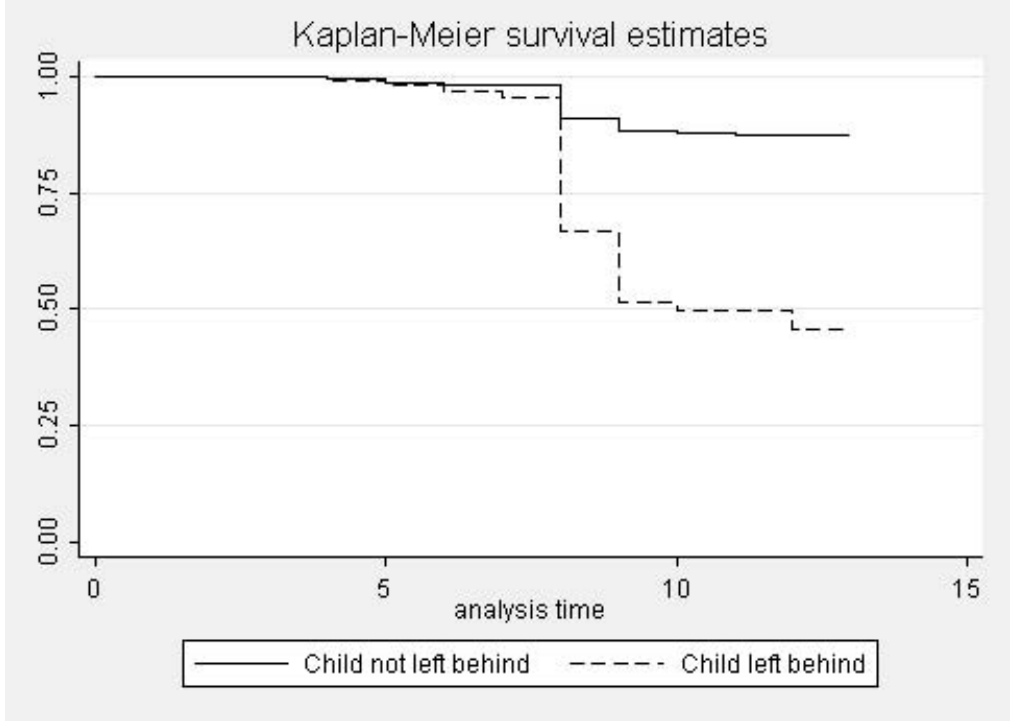

Table 4: Continuous Time Survival Analysis for School Attendance

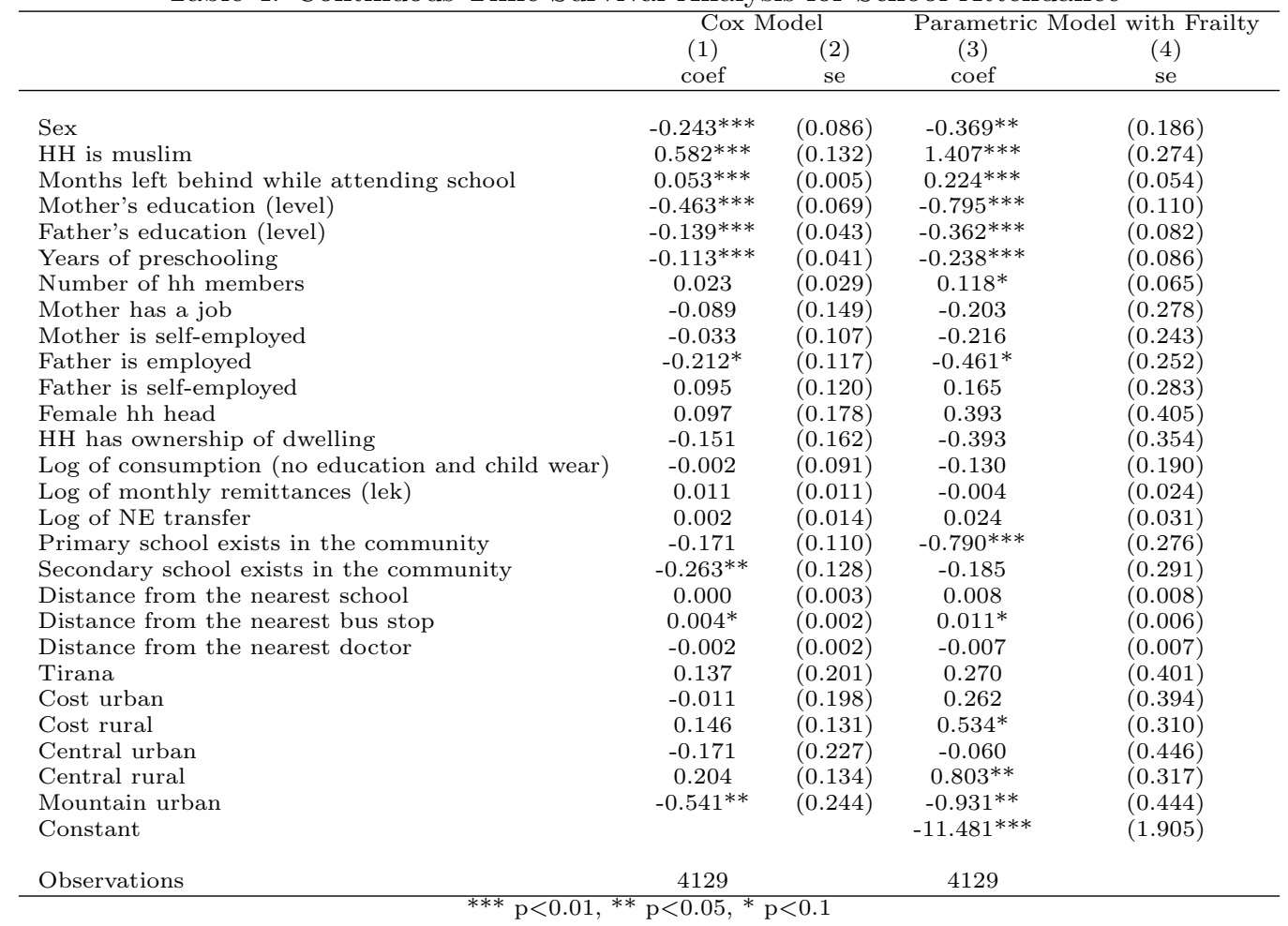


Table 5: Discrete Time Survival Analysis - Time-Varying Variables

\begin{tabular}{lcc} 
& \multicolumn{2}{c}{ Cox Model } \\
& $(1)$ & $(2)$ \\
& coef & se \\
\hline Sex & $-0.202^{* *}$ & $(0.090)$ \\
HH is muslim & $0.521^{* * *}$ & $(0.141)$ \\
Left behind with lag & $0.730^{* *}$ & $(0.360)$ \\
Mother's education (level) & $-0.457^{* * *}$ & $(0.072)$ \\
Father's education (level) & $-0.208^{* * *}$ & $(0.045)$ \\
Children under 18 in the household & -0.020 & $(0.043)$ \\
Number of hh members & $0.098^{* * *}$ & $(0.034)$ \\
Female hh head & 0.239 & $(0.387)$ \\
Distance from the nearest school & 0.005 & $(0.003)$ \\
Distance from the nearest doctor & -0.002 & $(0.003)$ \\
Distance from the nearest bus stop & $0.007^{* * *}$ & $(0.002)$ \\
Secondary school exists in the community & $-0.310^{* *}$ & $(0.133)$ \\
Primary school exists in the community & -0.040 & $(0.114)$ \\
tirana & 0.099 & $(0.204)$ \\
cost urban & 0.153 & $(0.194)$ \\
cost rural & $0.302^{* *}$ & $(0.131)$ \\
central urban & -0.263 & $(0.234)$ \\
central rural & 0.085 & $(0.133)$ \\
mountain urban & $-0.687^{* * *}$ & $(0.263)$ \\
Shock=death of earner & 0.336 & $(0.456)$ \\
Shock=job loss & 0.375 & $(0.453)$ \\
Shock=househols destroyed & 0.754 & $(0.585)$ \\
Shock=pyramide crisis & & \\
Observations & 0.283 & $(1.017)$ \\
& & \\
\hline & 27811 & \\
& &
\end{tabular}

distribution. This estimator allows to control for unobserved heterogeneity and the likehoodratio test confirms that heterogeneity cannot be neglected. The frailty model shows no relevant differences with respect to the Cox model. Both estimate a greater probability of school drop out due to having been left behind and to belonging to a Muslim household. A lower probability is associated with male gender, education of both parents and years of preschooling.

The negative effects of parental migration are also confirmed using the discrete time Cox model. This model allows to account for the dynamic effects of a time varying variable, namely, "left behind with $\operatorname{lag}^{17}$ ". Table 5 shows the discrete time model with time-varying covariates. Among the time-invariant covariates, as in all the other estimations, males are less at risk of dropping out than females. Belonging to a Muslim family or to a big family is related to a higher probability of leaving school. The episodes of being left behind are still negatively related to school drop outs controlling for the discrete nature of the collected data. The other time-varying variables (the micro and macroeconomic shocks) have no significant influence on dropping out, even though all of them present a positive sign.

The fact that all estimated models lead to similar results, gives more support to those findings.

\footnotetext{
${ }^{17}$ Here the variable "left behind" is constructed in such a way that the effects are continued also in the year following the left behind episode. This ensures the simultaneity of the episodes "drop out" and "left behind" when they happen sequentially over time, that otherwise would be lost.
} 


\section{Concluding remarks}

Several studies on children's welfare and migration have emphasized the positive effects of migration on children's outcomes deriving from the increase of economic resources to be invested in the accumulation of human capital. However, the positive income effects stemming from migrants' earnings are not without costs especially in the long-term, if children remain without parents for a long time during their development.

The absence of parents may entail psychological costs and change the decision-making process within the household, implying a modification of intra-household duties and responsibilities, and possibly inducing children of migrants to spend less time in school related activities. Children may end up dropping out of school or being held back one or more grades due to non-completion or unsatisfactory completion of their educational formation.

Most of the existing studies assessing the impact of parental migration episodes on children's welfare neglect the aspect of children's residence while one or both parents are working abroad, mainly because of lack of data. The survey data on migration used in this study allow to reconstruct retrospectively the children's schooling status during parental migration and effectively identify the long-term effects of the phenomenon.

Multiple choice models have been applied to evaluate the decision to send young children to school and school progression of children and adolescents. Then a duration analysis of school attendance with both discrete and continuous time models has been performed. All models have made use of retrospective information about children's school attendance and age at which they have been left behind to estimate the hazard function for the risk of dropping out of school.

The main finding of the analysis is that father's migration abroad negatively influences children's schooling in the long-term, increasing the probability of dropping out and of delaying school progression. For females, the impact is even higher compared to males. The negative impact of the phenomenon tends to become smaller the further in time from the actual events the migration episode is, while the effect increases with the length of the migration episodes.

The variables indicating the level of education of parents and household's social capital are relevant at all school levels in increasing the probability of school attendance. The economic status of the family and logistical constraints, like for example the distance from school or from public transports, influence the frequency of drop outs and delays among adolescents. The presence of the school in the community is the major element influencing attendance to non-compulsory schools, a fact that could point to the inadequacy of the supply of schools in Albania. Being "left behind" still has significant positive effects on the probability of dropping school in a duration analysis that controls for the discrete time nature of the collected data.

These findings claim for a greater attention to be paid to children of migrant workers by Albanian public authorities. They should take into account the fact that, even if migration is an important source of economic growth for the country, there can be costs associated with the loss of human capital in the long-term. The possible loss of human capital due to parents absence can have serious consequences in terms of future living standards. Hence, children's 
school attendance should be properly sustained in those households where one or both parents have migrated abroad with the proper instruments to compensate for the absence of parental guidance.

\section{References}

Alderman, H., J. Hoddinott, and B. Kinsey (2006) 'Long term consequences of early childhood malnutrition.' Oxford Economic Papers 58(3), 450

Calero, C., A.S. Bedi, and R. Sparrow (2009) 'Remittances, liquidity constraints and human capital investments in Ecuador.' World Development 37(6), 1143-1154

Cox, DR (1972) 'Regression models and life-tables.' Journal of the Royal Statistical Society. Series B (Methodological) pp. 187-220

Danaj, E., P. Festy, A. Guxho, M. Lika, and E. Zhllima (2005) 'Becoming an adult: challenges and potentials of youth in Albania.' Technical Report, INSTAT

Del Boca, D. (2003) 'Mothers, fathers and children after divorce: The role of institutions.' Journal of Population Economics 16(3), 399-422

Edwards, A.C., and M. Ureta (2003) 'International migration, remittances, and schooling: evidence from El Salvador.' Journal of Development Economics 72(2), 429-461

Ginther, D.K., and R.A. Pollak (2004) 'Family structure and children's educational outcomes: Blended families, stylized facts, and descriptive regressions.' Demography 41(4), 671-696

Gjonca, A., A. Aassve, and L. Mencarini (2008) 'Trends and patterns, proximate determinants and policies of fertility change: Albania.' Demographic research 19(11), 261-292

Heckman, James J., and Dimitriy V. Masterov (2007) 'The Productivity Argument for Investing in Young Children.' Review of Agricultural Economics 29(3), 446-493

Hildebrandt, N., and DJ McKenzie (2005) 'The Effects of Migration on Child Health in Mexico.(p. 35).' Washington, DC: The World Bank

Jenkins, S.P. (2004) 'Survival analysis.' Institute for Social and Economic Research, University of Essex.

Kiros, G.E., and M.J. White (2004) 'Migration, community context, and child immunization in Ethiopia.' Social Science \&3 Medicine 59(12), 2603-2616

Liang, Z., and Y.P. Chen (2007) 'The educational consequences of migration for children in China.' Social Science Research 36(1), 28-47 
Mangiavacchi, L., and P. Verme (2009) 'Evaluating Pro-poor Transfers When Targeting is Weak: The Albanian Ndihma Ekonomike Program Revisited.' Department of Economics-University of Florence, Working Papers Series

McCullagh, P. (1980) 'Regression models for ordinal data.' Journal of the Royal Statistical Society. Series B (Methodological) 42(2), 109-142

McKenzie, D., and H. Rapoport (2006) 'Can migration reduce educational attainment? Evidence from Mexico.' Policy Research Working Paper Series, World Bank

Orazem, P.F., and E.M. King (2008) 'Schooling in developing countries: The roles of supply, demand and government policy.' In Handbook of development economics Vol.4, ed. T.P. Schultz and J. Strauss (North Holland) pp. 3475-3559

Picard, N., and F.C. Wolff (2008) 'Measuring educational inequalities: A method and an application to Albania.' Journal of Population Economics pp. 1-35

Pudney, S., F. Mealli, and F. Rosati (2006) 'Measuring the Economic Vulnerability of Children in Developing Countries: An Application to Guatemala.' Working Papers 2006-28, ISER

Stark, O., C. Helmenstein, and A. Prskawetz (1997) 'A brain gain with a brain drain.' Economics Letters 55(2), 227-234

Stark, Oded, and Yong Wang (2002) 'Inducing human capital formation: migration as a substitute for subsidies.' Journal of Public Economics 86(1), 29-46

UNICEF (2009) 'Child Well-Being at a Crossroads: Evolving challenges in Central and Eastern Europe and the Commonwealth of Independent States.' Innocenti Social Monitor, UNICEF Innocenti Research Centre

WB (2006) 'Albania: restructuring public expenditure to sustain growth.' Report 36543 - AL, World Bank

_ (2007) 'Albania: Urban Growth, Migration and Poverty Reduction.' Report 40071 - AL, World Bank

Yamano, T., Y. Shimamura, and D. Sserunkuuma (2006) 'Living arrangements and schooling of orphaned children and adolescents in Uganda.' Economic Development and Cultural Change $54(4), 833-856$ 